\title{
Plant Growth Optimization by Vegetable Production System in HI-SEAS Analog Habitat
}

\author{
Joshua W. Ehrlich ${ }^{1}$ \\ Lockheed Martin Space Systems Company, Denver, Colorado 80210
}

\author{
Gioia D. Massa ${ }^{2}$, Raymond M. Wheeler ${ }^{3}$, Tracy R. Gill ${ }^{4}$, Charles D. Quincy ${ }^{5}$, Luke B. Roberson ${ }^{6}$ \\ National Aeronautics and Space Administration, Kennedy Space Center, Cocoa Beach, Florida 32899 \\ Kim Binsted ${ }^{7}$ \\ University of Hawai'i at Manoa, Honolulu, Hawai'i 96822 \\ and \\ Robert C. Morrow ${ }^{8}$ \\ Orbital Technologies Corporation, Madison, Wisconsin 53717
}

\begin{abstract}
The Vegetable Production System (Veggie) is a scientific payload designed to support plant growth for food production under microgravity conditions. The configuration of Veggie consists of an LED lighting system with modular rooting "pillows" designed to contain substrate media and time-release fertilizer. The pillows were designed to be watered passively using capillary principles but have typically been watered manually by the astronauts in lowEarth orbit (LEO). The design of Veggie allows cabin air to be drawn through the plant enclosure for thermal and humidity control and for supplying $\mathrm{CO}_{2}$ to the plants. Since its delivery to the International Space Station (ISS) in 2014, Veggie has undergone several experimental trials by various crews. Ground unit testing of Veggie was conducted during an 8-month Mars analog study in a semi-contained environment of a simulated habitat located at approximately 8,200 feet $(2,500 \mathrm{~m})$ elevation on the Mauna Loa volcano on the Island of Hawai'i. The Hawai'i Space Exploration Analog and Simulation (HI-SEAS) offered conditions (habitat, mission, communications, etc.) intended to simulate a planetary exploration mission. This paper provides data and analyses to show the prospect for optimized use of the current Veggie design for human habitats. Lessons learned during the study may provide opportunities for updating the system design and operational parameters for current Veggie experiments being conducted onboard the ISS and for payloads on future deep space missions.
\end{abstract}

\footnotetext{
${ }^{1}$ Orion Systems Engineer, Lockheed Martin, P.O. Box 179, MS S8090, Denver CO 80201

${ }^{2}$ Project Scientist, Mail Code: UB-A, Exploration Research and Technology, Kennedy Space Center, FL 32899

${ }^{3}$ Plant Physiologist, Mail Code: NE-S, Exploration Research and Technology, Kennedy Space Center, FL 32899

${ }^{4}$ Project Scientist, Mail Code: NE-S, Exploration Research and Technology, Kennedy Space Center, FL 32899

${ }^{5}$ Life Science and Food Production Innovation Manager, Mail Code: UB-1, Exploration Research and Technology, Kennedy Space Center, FL 32899

${ }^{6}$ Chemist, Mail Code: NE-L, Kennedy Space Center, FL 32899

${ }^{7}$ HI-SEAS Principal Investigator, University of Hawai'i at Manoa, Honolulu, HI 96822

${ }^{8}$ Principal Scientist, Orbital Technologies Corporation, Madison, WI 53717
} 


\section{Nomenclature}

$\begin{array}{ll}A P H & =\text { Advanced Plant Habitat } \\ B E O & =\text { Beyond Earth Orbit } \\ D A P & =\text { Days After Planting } \\ E D M & =\text { Edible Mass } \\ E M & =\text { Exploration Mission } \\ E S A & =\text { European Space Agency } \\ H I-S E A S & =\text { Hawai'i Space Exploration Analog } \\ & \\ I S S & =\text { and Simulation }\end{array}$

\begin{tabular}{|c|c|c|}
\hline$L E D$ & $=$ & Light Emitting Diode \\
\hline$L E O$ & $=$ & Low Earth Orbit \\
\hline NextSTEP & $=$ & $\begin{array}{l}\text { Next Space Technologies for } \\
\text { Exploration Partnerships }\end{array}$ \\
\hline & $=$ & Photosynthetic Active Radiation \\
\hline & . & Pearson's Correlation Coefficient \\
\hline$P P F D$ & $=$ & Photosynthetic Photon Flux Density \\
\hline & $=$ & Relative Humidity \\
\hline & & hade Avoidance Syndrome \\
\hline
\end{tabular}

\section{Introduction}

$\mathrm{T}_{\mathrm{t}}^{\mathrm{h}}$ he Veggie unit is a low cost, simple plant growth system that could be stowed in a small space and easily deployed for various space settings (Morrow et al, 2005). Since its installment in 2014, Veggie has served an important role onboard the ISS: providing astronauts onboard the orbiting outpost a source of fresh greens and vegetables grown entirely in microgravity (Massa et al, 2017). Experiments for optimizing growth conditions and operations for plants and food production in space settings have been the focus of various ongoing studies (Richards et al, 2004, 2005). The research required to define parameters for optimizing future plant growth payloads will provide critical information for supporting BEO human exploration. The definition and maturation of plant growth schedules, impacting current and future science payloads - such as Advanced Plant Habitat (APH) - as well consideration for orbital spacecraft designs - such as the Next Space Technologies for Exploration Partnerships (NextSTEP) habitat and Mars Base Camp - make further investigation with Veggie necessary to advance space food production technology.

\section{HI-SEAS Background}

The Hawai'i Space Exploration and Analog Simulation (HI-SEAS), a NASA Human Factors and Behavioral Performance funded research program, is a long-duration planetary surface analog focused on investigation of crew composition, cohesion, and performance. Located on the slopes of an active volcano in Hawai'i, HI-SEAS presents a unique combination of Mars mission conditions and is one of a small number of analogs capable of operating for very longdurations (8 months or longer). Since 2013, HI-SEAS has hosted four analog missions ${ }^{1}$, ranging from four to twelve month durations with a total of six crew members in each mission. The HI-SEAS facility is

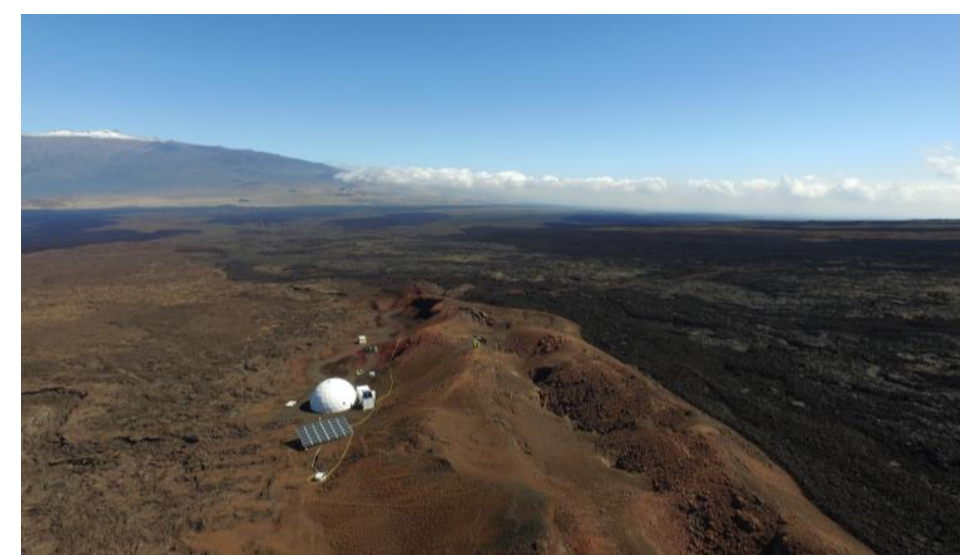

Figure 1. The HI-SEAS habitat residing on the slopes of the Mauna Loa volcano on the island of Hawai'i. (image credit: HISEAS) comprised of a $13,000 \mathrm{ft}^{3}$ geodesic Dome (crew living space and laboratory, i.e. "habitat") with 1,200 $\mathrm{ft}^{2}$ of usable floor space. Mars-analog simulations are regarded as the most comprehensive tools for understanding key human psychology and social behavior, optimizing development and usage of critical expedition assets (Leon et al, 2002), while living in an isolated, confined 'space' in a location similar in landscape to that of the red planet.

\footnotetext{
${ }^{1}$ The information and data presented in this paper were produced during Mission V of the HI-SEAS program. The 8-month Mars analog was comprised of six crew members and took place January $19^{\text {th }}-$ September $17^{\text {th }}$, in the year 2017 .
} 


\section{Plants in Space}

\section{Lighting}

In a controlled environment, lights must provide an adequate flux of photosynthetic active radiation (PAR) to drive plant growth, as well as radiation to control photomorphogenic and phototropic responses in plant growth and development (Folta and Childers, 2008). Both red light, via phytochrome, and blue light, via cryptochrome, are important for controlling photomorphogenic responses (Goins et al, 1996). Red light is important as it promotes the development of the photosynthetic apparatus and accumulation of starch in plants, while blue light helps in the formation of chlorophyll, chloroplast development, photomorphogenesis and stimulates stomata opening as well (Heo et al, 2002; Folta and Maruhnich., 2007). Blue lights are also known to suppress hypocotyl elongation and induce biomass production, while red light induces hypocotyl elongation and leaf area expansion.

Overall, plants absorb approximately $90 \%$ of red or blue light, and only 70-80\% of green light (Jokhan et al, 2011). Plant canopies, especially those with dense foliage, can interfere with red and blue spectral distributions. This is apparent in plant species found in the understory, where red and blue light combinations are absorbed by overarching leaves (Folta and Maruhnich, 2007). This depletion forces seeds to elongate upwards toward the sun, soaking in the unfiltered green and far-red light that the plants rely on to thrive under low fluence rates (Wang and Folta, 2013). The addition of green light has also been found to induce a low-light growth pattern typically found in light-depleted/shaded conditions (Zhang et al, 2011).

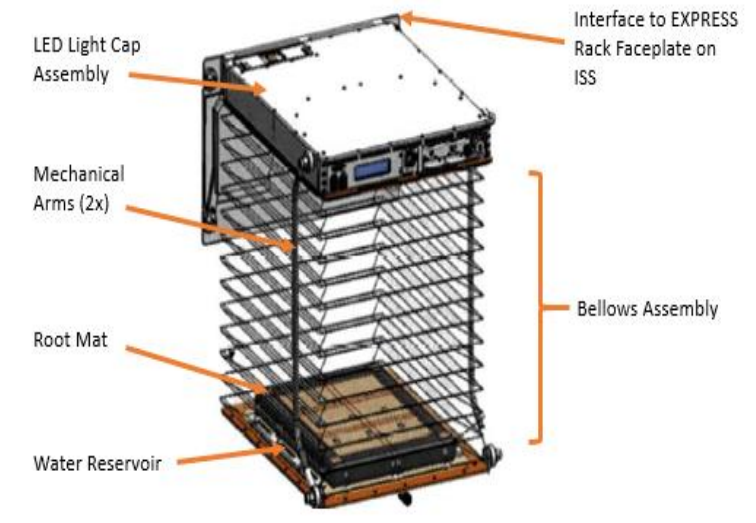

Figure 2. CAD model of Veggie, built by ORBITEC Technologies, Inc., primarily focused on the demonstration of successful food production in microgravity (image credit: ORBITEC).

\section{Water and Nutrient Delivery}

Factors such as light, air quality, and ventilation are known to have significant impacts on plant growth in space; however, none of these have more constraining effects on the success of plant growth than the control of water and nutrients in the root zone (Steinberg et al, 2002). Plants require a variety of mineral nutrients for growth; a total of sixteen major elements (Tsao and Okos, 1997). These elements can come in various forms applied through several different means to reach the roots of the plants, however the main elements (carbon, hydrogen, oxygen) are absorbed through the atmosphere and water. Whether achieved through active or passive delivery, nutrient presence in the root zone is vital to the plants for absorption over its growth cycle especially for replacing that which is lost due to the plant's transpiration over time.

\section{Air Quality}

The atmospheric composition onboard a space station is vastly different than that found on Earth, and if not observed and controlled properly may lead to adverse impacts on both plant specimens and crew. Major contaminant sources can include ethylene, methane, alcohols, organosilicones, and other minor contaminants. Ethylene, a gaseous plant hormone, has been the culprit in several failed plant experiments onboard Mir and the Space Shuttle. Environmental control (thermal, $\mathrm{CO}_{2}$, and humidity) in Veggie is provided by a continuous flow of ISS cabin air through the enclosure (i.e. light cap assembly; see Fig. 2 above). Thus, the Veggie environment closely tracks the ISS cabin environment.

\section{Plant Substrate}

The root zone is generally contained to support crop development, which with a solid substrate provides the plant structure as well as a passive water delivery system the roots utilize. Some of the primary areas considered in substrate selection include moisture holding capabilities and aeration for root zones, especially that sized ideally to the Veggie pillows (Massa et al, 2013). 


\section{Scope \& Objectives}

The purpose of this study is to identify the optimal parameters for growing plants in the HI-SEAS habitat using Veggie. Prior studies on ground and in flight unit models of the scientific payload have been conducted, however, the methodology for defining the ideal experiment characteristics on a plant-byplant basis requires a more rigid and extensive approach. The set of parameters (shown in Table 1) investigated over the course of this study included:

1) Change in displacement $(\Delta y)$ between the pillow upper surfaces and the LED light cap

2) Measured Photosynthetic Photon Flux Density (PPFD) outputs (LED light emission measurements) on largest/highest exposed plant surfaces

3) Impacts on plants from daily exposure of temperature, humidity and $\mathrm{CO}_{2}$ by local crew activities

4) Measured edible mass of plant specimen products at completion of each growth cycle

5) Plant growth dimensions, correlated with the environmental parameters

\section{Experiment Setup and Process}

\section{A. Plants}

Green, leafy Brassica rapa L. ('Tokyo Bekana' Chinese Cabbage) cultivars were used in the single control and three test trials. Chinese Cabbage cultivars was chosen based on its robustness, excellent rapid growth, good elemental profile, and palatability (Massa et al, 2015). In addition, these cultivars are already under study as part of the VEG-03 testing recently conducted onboard the ISS (Fig. 3).

\section{B. Environmental Conditions (HI-SEAS Habitat)}

The habitat set temperature - controlled by the X-300 Hydronic heating unit (Rheem Manufacturing Company, Atlanta, GA) - ran in a "sun up" (06002200) cycle at $67.5^{\circ} \mathrm{F}\left(19.7^{\circ} \mathrm{C}\right)$ and "sun down" cycle at $60.0^{\circ} \mathrm{F}\left(15.6^{\circ} \mathrm{C}\right)$. Interior temperature $\left( \pm 1^{\circ} \mathrm{F}\left( \pm 0.5^{\circ} \mathrm{C}\right)\right)$, $\mathrm{RH}( \pm 0.1 \%)$, and $\mathrm{CO}_{2}( \pm 30 \mathrm{ppm}, \pm 2 \%$ measured value) were measured by the Veris CWL sensor (Veris Industries, Tualatin, OR). This 3-in-1 equipment was located $\sim 10$ feet $(3.05 \mathrm{~m})$ away from the Veggie growth chamber. Water was transported to the HI-SEAS facility by contracted services. Infrequent loss in power would occur, which would temporarily ( 20 minutes, average) shut off all lighting and passive humidity control to Veggie, when power would be switched over from solar to generator, and vice versa.

\section{Environmental Conditions (Veggie)}

The Veggie Prototype (Fig. 4) is equipped with four humidity and ventilation control fans. RH $( \pm 5 \% \mathrm{RH})$ and temperature levels $\left( \pm 0.1^{\circ} \mathrm{F}\left(-17.83^{\circ} \mathrm{C}--17.72^{\circ} \mathrm{C}\right)\right)$ were measured in the Veggie growth chamber via two Cornwall SH-101 thermo-hygrometer sensors (Cornwall Electronics, Truro, UK). Two sensors helped to give an average approximation. $\mathrm{CO}_{2}$ levels inside the Veggie Prototype, however, was not measured. Light emissions were measured by an Apogee Instruments M-200 Series Quantum Meter (Omega Engineering, Fort Collins, CO), which was used to monitor PPFD at seed and plant canopy levels during the 28-day growth cycles.

\section{Methods}

\section{Substrate Preparation}

The substrate of choice for the Veggie pillows was based on the mixture of media and fertilizer used both in Veggie ground testing and in the VEG-01 and VEG-03 flight experiments. Arcillite (Turface Proleague, Profile Products, LLC.) was acquired and used as the primary substrate for pillow media. The substrate, however, was not pre-sieved 
to obtain a specific particle size, as is standard practice for Veggie ground testing (Massa et al, 2016). A polymercoated controlled release fertilizer (18-6-8, type 180-day, Florikan) was mixed with the arcillite at a rate of $7.5 \mathrm{~g} / \mathrm{L}$ of dry Turface.

\section{Pillow Preparation}

Veggie pillows, an expandable Teflon ${ }^{\mathrm{TM}}$ coated Kevlar ${ }^{\circledR}$ bag, were used for housing the seeds during the study. The pillows, built by ORBITEC (Madison, WI) interfaced directly to the passive watering system within the pillow box. A silicon foam gasket, used for seed placement, sits within the pillow casing material between the top surface and the root growth zone (substrate capacity of $250 \mathrm{~mL}$ ). A $12 \mathrm{~cm} \times 2.3 \mathrm{~cm}$ piece of wicking material was inserted through the gasket's central slit, with a $1.8 \mathrm{~cm}$ wick removed outside the gasket. Pre-measured media and fertilizer was deposited in each pillow. Seeds were sown at a density of two per pillow, with the scared end of the seed pointed towards the pillow root zone. Each wick was closed to provide adequate moisture during the germination process. Following this step, each pillow was placed in the pillow box container in a $2 \mathrm{x}$ 3 grid (Fig. 5).

\section{Pillow Box Preparation}

A $45 \mathrm{~cm}$ x $26.75 \mathrm{~cm}$ x $10.75 \mathrm{~cm}$ molded, fiberglass container was used to house the six pillows in a single, modular unit. The passive watering system consisted of high density foam surrounded by polypropylene wicking material (KIMTECH Pure W4 Dry Wipers, Kimberly-Clark Professional), with an Ultem semirigid sheet sandwiched in-between both materials. The high-density foam was cut to size to the fit the pillow box, producing a positive pressurized seal around the foam perimeter for operating the passive watering system. Slits were cut on the top surface of the wicking material for air pockets to escape, providing an ideal flow path for water to be absorbed by the pillows.

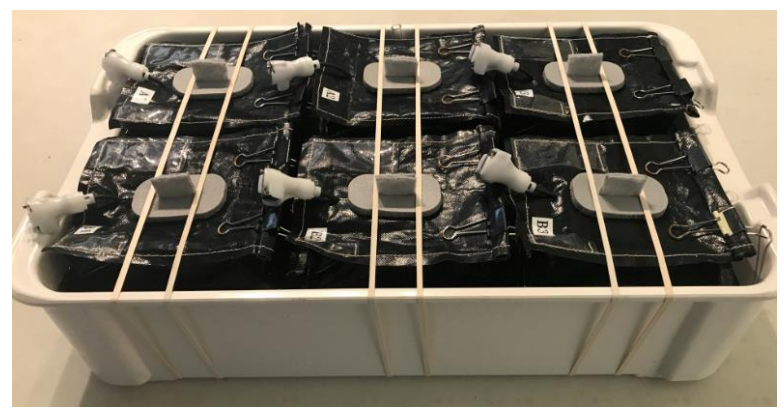

Figure 5. Veggie pillow box container with six prepared pillows. When inserted into the Veggie growth chamber, those pillows on the left-side (back row in image) of the box were labeled as "A-side pillows", numbered 1-3, front to back. On the rightside (front-row in image) were the "B-side pillows", following the same numbering format as before. When referring to seed \#1 versus seed \#2 for each pillow, the former is closest to the pillow's quickdisconnect hardware.

Table 1. Design parameters for each trial conducted in the study. 'Tokyo Bekana' light schedule values are the hours each light segment ran, shown in a 24-hour format. Red:Blue (R:B), Red:Blue:Greeb (R:B:G), Green (G).

\begin{tabular}{|c|c|c|c|c|c|c|}
\hline Trial & Seed Type & $\begin{array}{l}\text { Water } \\
\text { Supply, } \\
\text { L }\end{array}$ & Manual Watering Schedule & Light Schedule & $\begin{array}{l}\text { Emissions } \\
\text { Output, } \\
\mu \mathrm{mol}^{* \mathrm{~m}^{-2}}{ }^{*} \mathrm{~s}^{-1}\end{array}$ & $\begin{array}{c}\Delta y \\
\text { in }\end{array}$ \\
\hline Control \#1 & \multirow{4}{*}{$\begin{array}{l}\text { 'Tokyo } \\
\text { Bekana' } \\
\text { Chinese } \\
\text { cabbage }\end{array}$} & 14.6 & $\begin{array}{l}5 \text { L H2O @ start, } 600 \text { mL } 1 \\
\text { DAP, bi-daily 2-28 DAP, } \\
\text { 100mL/pillow }\end{array}$ & $\begin{array}{l}\text { On: } \\
(0900-2100) ; \\
\text { Off: } \\
(2100-0900)\end{array}$ & $\mathrm{R}: \mathrm{B}=188.6$ & 7.0 \\
\hline Test \#1 & & 15.1 & $\begin{array}{l}5.5 \text { L H2O @ start, } 600 \text { mL } 1 \\
\text { DAP, bi-daily 2-28 DAP, } \\
\text { 100mL/pillow }\end{array}$ & $\begin{array}{l}\text { On: } \\
(0900-2100) \\
\text { Off: } \\
(2100-0900)\end{array}$ & $\begin{array}{l}\text { R:B = 171.66; } \\
\text { Post-11 DAP } \\
\quad=188.6\end{array}$ & $\begin{array}{l}7.25, \\
\text { adjusted } \\
\text { to } 8 \text { in. @ } \\
19 \text { DAP }\end{array}$ \\
\hline Test \#2 & & 15.05 & $\begin{array}{l}5 \text { L H2O @ start, } 600 \text { mL } 1 \\
\text { DAP., } 450 \text { mL } 2 \text { DAP, bi-daily } \\
\text { 3-28 DAP, 100mL/pillow }\end{array}$ & $\begin{array}{l}* 24-\text { hour lights on } \\
\text { R:B:G=(0800-0900; } \\
\text { 2100-2200); R:B=(0900- } \\
\text { 2100); G=(2200-0800) }\end{array}$ & $\begin{array}{c}\mathrm{R}: \mathrm{B}: \mathrm{G}= \\
170.5 \\
\mathrm{R}: \mathrm{B}=188.6 \\
\mathrm{G}=22.33\end{array}$ & 7.25 \\
\hline Test \#3 & & 15.05 & $\begin{array}{l}\text { 5 L H2O @ start, } 600 \text { mL } 1 \\
\text { DAP., } 450 \text { mL } 2 \text { DAP, bi-daily } \\
\text { 3-28 DAP, 100mL/pillow }\end{array}$ & $\begin{array}{l}* 24-\text { hour lights on } \\
\mathrm{R}: \mathrm{B}: \mathrm{G}=(0800-0900 ; \\
2100-2200) ; \mathrm{R}: \mathrm{B}=(0900- \\
2100) ; \mathrm{G}=(2200-0800)\end{array}$ & $\begin{array}{c}\mathrm{R}: \mathrm{B}: \mathrm{G}= \\
170.5 \\
\mathrm{R}: \mathrm{B}=188.6 \\
\mathrm{G}=22.33\end{array}$ & 7.25 \\
\hline
\end{tabular}




\section{Results and Discussion}

\section{A. Testing}

\section{Control \#1}

Control test \#1 sought to reduce temperature loads, which was believed to have a direct impact on the RH levels within the chamber. 'Tokyo Bekana' Chinese Cabbage was the crop chosen for this trial. A direct correlation between high PPFD values (> $\left.160 \mu \mathrm{mol}^{*} \mathrm{~m}^{-2}{ }^{*} \mathrm{~s}^{-1}-170 \mu \mathrm{mol}^{*} \mathrm{~m}^{-} 2 * \mathrm{~s}^{-1}\right)$ and increased edible masses produced (shown in Table 2) was confirmed. Width measurements had a much greater correlation to harvest production than the depth, a candidate factor of control for playing in the overall success of the crop. This is further explained later in this study.

It is suspected that photonic reflectance distributed by the bellows may have aided in specific edible mass pillows (e.g. A3). Plants with greater volumes captured higher photonic outputs from the LED's, but by doing so blocked out any light from reaching adjacent plants (Fig. 6), thus impacting their edible mass products. Pillows A2 \& B2 had the highest measured irradiance levels and accounted for $44.3 \%$ of the total edible mass. Pillow A3, adjacent to both these pillows, produced the least mass than any of the other pillows.

\section{Test \#1}

Plants grown in test \#1 were far more symmetric in shape compared to those grown in control \#1, proving a strong correlation between geometry and edible mass produced (shown in Table 2). Seven of the twelve germinated plants toppled over during the 28-day experiment, causing the final growth heights not to be as accurate as earlier measurements (two of the seven toppled-over plants exceeded that height at 28 DAP). The PCC values shown in Table 2 provides evidence that points to a possible correlation between average seed growth with edible mass production, specifically the data associated with all seed \#1's within each pillow. Seed \#1 points to a potential valuation in optimal growth rate for the 'Tokyo Bekana', as the greatest edible mass products corresponding to growth values $>0.205 \mathrm{~cm} /$ day. The data corresponding to seed \#2 is potentially skewed as any seed, whether in the same pillow or adjacent to another, can impact growth based on shading that will cause less light from reaching a plant.

Table 2. Average $W$ and $D$ measurement for seeds \#1 \& 2 (if applicable) in test \#1. Unlike control \#1, test \#1 had more significant PCC values between the plant dimensions and edible masses at the end of the growth cycle

Figure 6. The orange and yellow arrows indicate the longitudinal and latitudinal directions of growth for each 'Tokyo Bekana' plant in control \#1. The plant shoot system, including both the hypocotyl and petioles, directed themselves towards the highest concentration of PPFD.

\begin{tabular}{|c|c|c|c|c|c|}
\hline Pillow & $\begin{array}{c}\operatorname{Avg~W}, \\
\text { cm }\end{array}$ & $\begin{array}{c}\text { Avg D, } \\
\text { cm }\end{array}$ & $\begin{array}{c}\text { Edible } \\
\text { Mass. } \\
\text { g }\end{array}$ & $\begin{array}{c}\text { PCC } \\
\text { (EDM:W) }\end{array}$ & $\begin{array}{c}\text { PCC } \\
\text { (EDM:D }\end{array}$ \\
\hline A1 & 10.25 & 10.25 & 2.31 & \multirow{6}{*}{$89.0 \%$} & \multirow{7}{*}{$86.1 \%$} \\
\hline A2 & 7.30 & 6.55 & 1.47 & & \\
\hline A3 & 12.40 & 11.80 & 6.23 & & \\
\hline B1 & 4.45 & 4.05 & 0.30 & & \\
\hline B2 & 9.15 & 11.80 & 3.46 & & \\
\hline B3 & 3.85 & 6.65 & 0.93 & & \\
\hline Total & & & 14.70 & & \\
\hline
\end{tabular}

\section{Test \#2}

Similar to results collected in test \#1, width and depth measurements provided strong indicators to the edible mass produced by each pillow. While the average growth rate for the seeds in test \#2 was faster than that of test \#1 $0.147 \mathrm{~cm} /$ day versus $0.173 \mathrm{~cm} /$ day (a $17.7 \%$ increase in test \#2), respectively - the edible mass products were lower than that seen in test \#1 (a 66.2\% decrease). Still, the outcome produced significant PCC values (shown in Table 3), suggesting a strong correlation. The data from test \#2 identifies an average growth rate of $0.200 \mathrm{~cm} /$ day was achieved. It was also observed that the shoot systems rigid compared to previous trials. When collected PPFD measurements inside the chamber, the plants seemed to be unaffected by any unintended contact. 
Table 3. Growth rates per 'Tokyo Bekana' seed and its correlation to edible masses within each pillow for test \#2. The growth rates list is reflective either of 1) the maximum height reached w.r.t the corresponding DAP immediately following a plant topple-over event or 2) a transition from a dynamic to a static state of growth (height change by $\leq 1.3 \mathrm{~cm}$ ) within a two-day period. The PCC column is in reference to all six pillows used in the trial. "N/A" is indicative of no growth achieved by that seed.

\begin{tabular}{lcccccccc}
\hline \multirow{2}{*}{ Seed 1 } & A1 & A2 & A3 & B1 & B2 & B3 & PCC \\
& $\begin{array}{c}\text { Growth Rate } \\
\text { (cm / \# days at max height) }\end{array}$ & 0.145 & 0.193 & 0.300 & N/A & 0.300 & 0.092 & \\
\cline { 2 - 8 } Seed 2 & Edible Mass (g) & 0.67 & 1.20 & 2.25 & N/A & 1.33 & 0.74 & \\
& $\begin{array}{c}\text { Growth Rate } \\
\text { (cm / \# days at max height) }\end{array}$ & 0.042 & 0.200 & 0.042 & N/A & N/A & 0.241 & \multirow{2}{*}{$91.9 \%$} \\
\cline { 2 - 9 } & Edible Mass (g) & $0.00^{*}$ & 1.12 & 0.57 & N/A & N/A & 0.96 & \\
\hline Pillows & Total Mass (g) & 0.67 & 2.32 & 2.82 & 2.00 & 1.33 & 1.70 & \\
\hline
\end{tabular}

*Pillow A1, seed \#1 germinated, however, hardware to measure edible mass product did not provide adequate sensitivity as plant specimen was too insignificant to measure.

\section{Test \#3}

Test \#3 witnessed germination by eleven of the twelve 'Tokyo Bekana' seeds. Notably, the most intriguing aspect of the growth trends was the success of the edible mass products by seed \#1's. Growth rates above $0.213 \mathrm{~cm} /$ day produced significant edible mass totals (mainly seed \#1's), while seeds within the same pillow saw suboptimal growth rate values with insubstantial edible mass products. The only case where this was present was seed \#2 in pillow A2, where the second highest PPFD values were measured (behind A1). Plant rigidity was confirmed in test \#3, similar to test \#2. This coincides with the previous hypothesis that green light provided added integrity to the plant hypocotyl. PCC values in Table 4 show strong correlations between

Table 4. While results gathered both in test \#3 and previous trials show positive trends between total edible mass and the depths achieved by each plant, width of the 'Tokyo Bekana' plant is consistent with the performance expected at harvest.

\begin{tabular}{|c|c|c|c|c|c|}
\hline Pillow & $\begin{array}{c}\operatorname{Avg} W, \\
\text { cm }\end{array}$ & $\begin{array}{c}\text { Avg D, } \\
\text { cm }\end{array}$ & $\begin{array}{c}\text { Edible } \\
\text { Mass, } \\
\text { g }\end{array}$ & $\begin{array}{c}\text { PCC } \\
\text { (EDM:W) }\end{array}$ & $\begin{array}{c}\text { PCC } \\
\text { (EDM:D })\end{array}$ \\
\hline A1 & 2.15 & 3.95 & 0.40 & \multirow{6}{*}{$94.0 \%$} & \multirow{6}{*}{$82.2 \%$} \\
\hline A2 & 9.50 & 10.20 & 3.59 & & \\
\hline A3 & 7.85 & 7.35 & 2.93 & & \\
\hline B1 & 2.00 & 2.55 & 0.31 & & \\
\hline B2 & 8.40 & 6.95 & 4.48 & & \\
\hline B3 & 10.60 & 6.90 & 3.67 & & \\
\hline Total & & & 15.38 & & \\
\hline
\end{tabular}
the average width dimension and edible mass product, which was confirmed in previous trails.
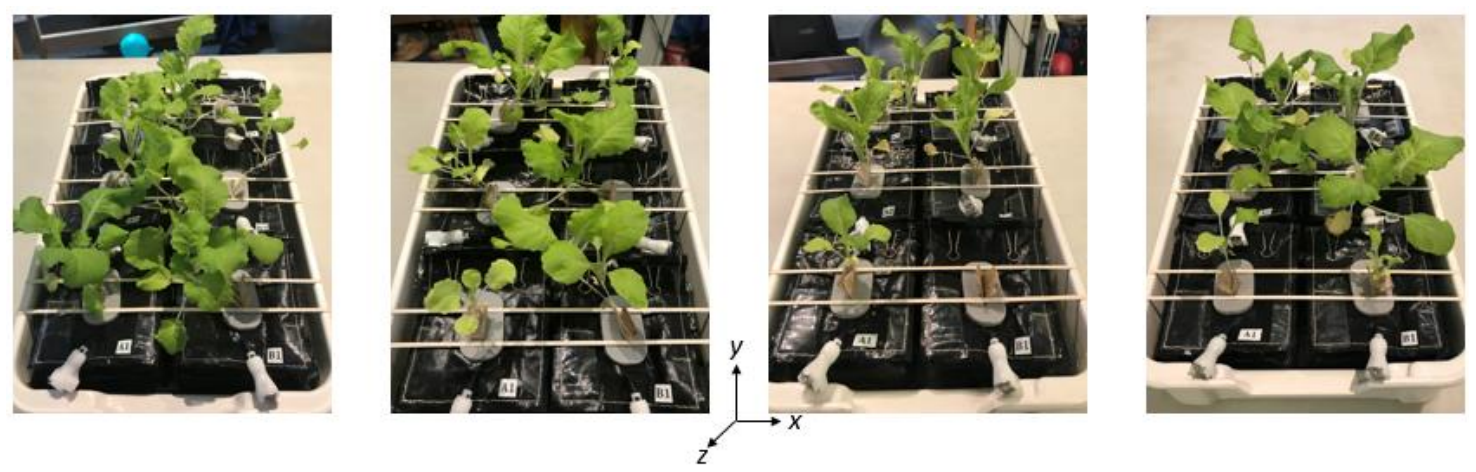

Figure 7. 'Tokyo Bekana' results from each 28-day growth experiment conducted in the HI-SEAS habitat. From left to right: Control \#1; Test \#1; Test \#2; Test \#3. 


\section{B. Correlation Analyses}

\section{Plant Growth vs. Edible Mass}

Considering the plant growth rates for the three highest edible masses achieved in each trial, an average growth rate of $0.233 \mathrm{~cm} /$ day per plant was achieved. The findings of this study, with verification by its PCC values, proved that plant width has a significant effect on the overall success of the plant, as well can serve as an indicator to its potential edible mass production at harvest. While it may be assumed a geometrical growth may be the best scenario, it can be argued otherwise that a plant with an asymmetrical geometry, when driven by the width (growth in the ' $x$ ' direction), is the ideal growth pattern for the plant to follow (at first). This can also prove to be beneficial when determining crop success (final masses shown above in Fig. 7) as measuring a plant's initial width at the start of the growth cycle versus measuring the plant area later on can give potential indication to an edible mass product as well the system's overall health.

\section{Addition of Green Light}

The addition of green wavebands appears to cause leaves to lift upward and towards the light source along with greater elongation of petioles - evidence of photomorphogenic changes consistent with Shade Avoidance Syndrome (SAS) (Zhang et al, 2011). While noted that the effects of green light oppose those directed by red and blue wavebands (Folta and

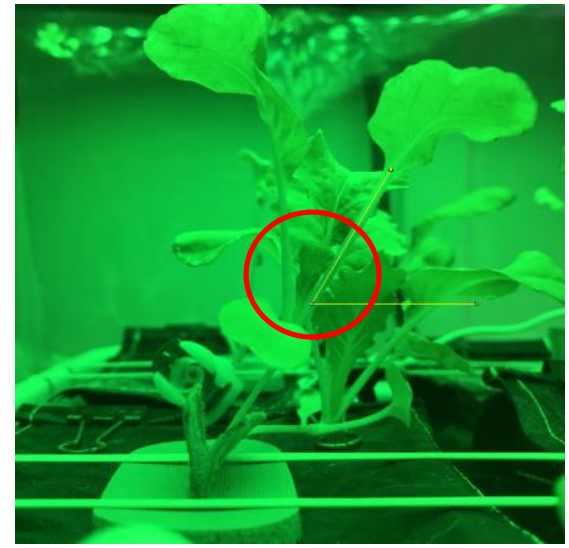

Figure 8. 'Tokyo Bekana' leaf (circled) at internode captured 21 DAP of Test \#3 at the start ( 2100) of the 10-hour green light overnight exposure. 'Yellow' line in image was an angular measurement $\left(59.5^{\circ}\right)$ collected via ImageJ.

Maruhnich, 2007), Figs.

$8 \& 9$ show leaf growth at the internode of the plant. This evidence, thus, proposes the theory that while blue light may be responsible for the formation of chlorophyll and development of chloroplasts (Heo et al, 2002), plants may also use green light to 1) increase photosynthesis through the excitement of chloroplasts located deep in the mesophyll and 2) activate the use of chlorophylls as photosynthetic pigments by maintain higher yields for the entire leaf both in strong and weak light conditions (Terashima et al, 2009). The graph in Fig. 10 provides evidence that average PAR level for the green waveband reached seed-level and remained relatively constant over each growth cycle, while red and blue wavebands decreased from start-to-end. This data

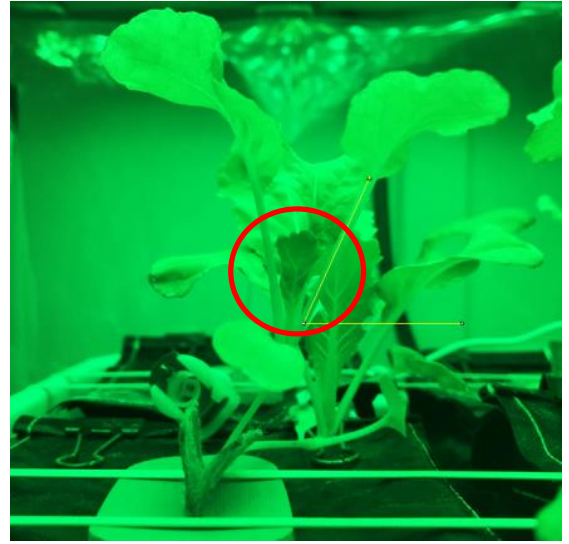

Figure 9. Following the 10-hour green light exposure period, both the 'Tokyo Bekana' petiole and leaf has increase in length and area, respectively. The plant had an adjusted, angular inclination of $65.5^{\circ}$.

Light Segment Average PPFD Measurements

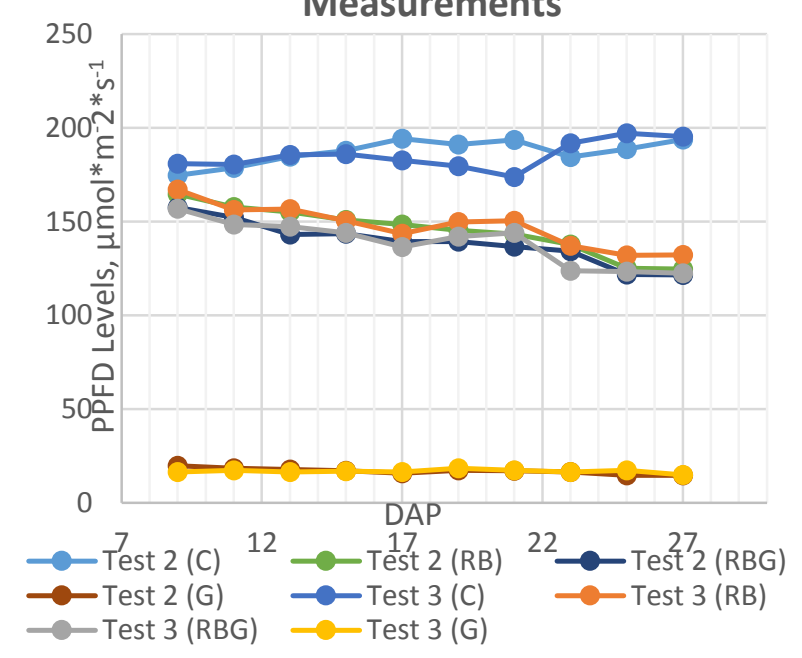

Figure 10. Lines represent PPFD levels for 9-27 DAP for tests \#2 \& \#3 only. Light levels at the canopy (C) have slight drops due to plants toppling over, causing average PPFD values to decrease. Levels for those wavebands measured at the pillow seed-level (S) have similar trends for both R:B \& R:B:G light outputs. 
confirms that while canopy density increased over the course of the growth cycle, green light reached the seed level and was minimally disturbed by those obstructions.

\section{Analog Impacts}

Outside of that research, the impact from crew members daily life on the plant growth trails conducted in this study, including the habitat environment and group activities, was studied over the eight months. These impacts, correlating habitat telemetry with Veggie growth chamber measurements, included internal temperature, relative humidity, and $\mathrm{CO}_{2}$ exhaustion. The probability of significance $(\alpha)$, which provides valuation of the probability the data provided has a strong correlation and not collected by chance, is provided. $\alpha$ values of $5 \%$ and below are considered highly significant, meaning the data provide has a $1 / 20^{\text {th }}$ chance of being a false-positive value.

\section{Temperature}

Average temperature inside the Veggie growth chamber for test \#'s $2 \& 3$ was $66.5^{\circ} \mathrm{F}\left(19.2^{\circ} \mathrm{C}\right)$. While this value falls below the nominal $73.4^{\circ} \mathrm{F}\left(23^{\circ} \mathrm{C}\right)$ value for a 16-hour light cycle temperature limit ${ }^{2}$, that value was expected to remain below an assumed upper limit as green light only caused temperatures to either remain constant or drop. An average habitat temperature of $65.1^{\circ} \mathrm{F}\left(18.4^{\circ} \mathrm{C}\right)$ fell in the nominal, steady-state range - $64.1^{\circ} \mathrm{F}-80.3^{\circ} \mathrm{F} \quad\left(17.8^{\circ} \mathrm{C}-26.8^{\circ} \mathrm{C}\right)$ - for vehicle atmospheres (shown in Fig. 11) (Anderson et al, 2015). Average temperatures outside the habitat was $66.1^{\circ} \mathrm{F}$ $70.1^{\circ} \mathrm{F}\left(18.9^{\circ} \mathrm{C}-21.2^{\circ} \mathrm{C}\right)$, which is believed to have had a relatively small impact on Veggie with the minimal insulation present in the habitat's design (flooring, wall material and layering, ventilation, sealed interfaces). It is believed that the centralized location of Veggie within the habitat, where most of the crew were present (1-3 persons, average 16.5 hours/day), caused growth chamber temperatures to remain in a relatively "comfortable" zone for plant growth. PCC values relating to internal temperatures between the habitat and Veggie growth chamber for the four trials measured are shown in Table 5.

\section{Relative Humidity}

Average RH levels reached a min and max of $32.6 \%$ and $55.6 \%$, respectively, with a mission average of $43.8 \%$. These levels do not breach the assumed crew comfort level limits nor would pose any threat to vehicle systems (Anderson et al, 2015). Test \#'s' 1-3 PCC measures indicate strong correlations between the two (shown in Table 6). The altitude of the habitat $(8,200$ feet $(2,500 \mathrm{~m})$ above sea level) will influence the water vapor partial pressure external

\footnotetext{
2 Per the NASA Life Support Baseline Values and Assumptions (c. 2015), a 16-hour light cycle temperature for Lettuce is the only plant closely resembling the 'Tokyo Bekana' Chinese Cabbage tested in this study. Thus, its corresponding value was used for comparison.
}

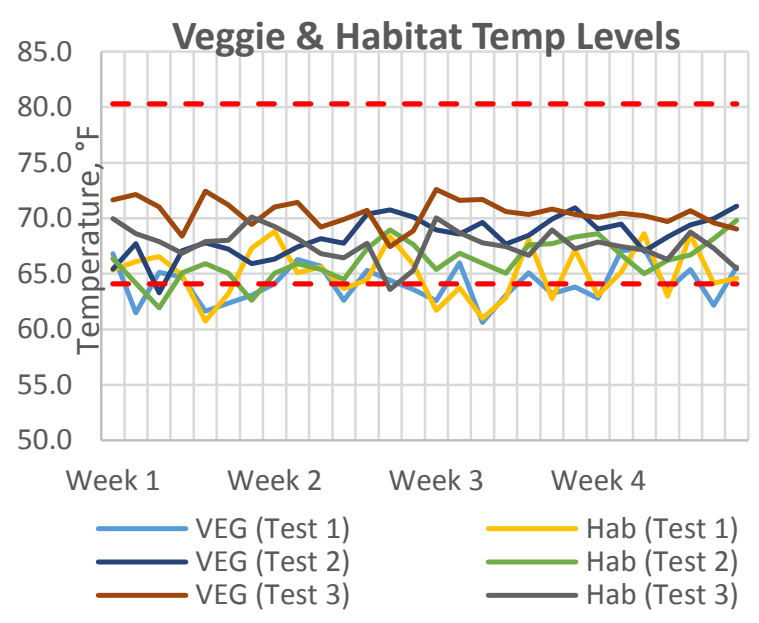

Figure 11. Relationship between the temperature measurements with the Veggie growth chamber and habitat internal temperatures. The 'red' dashed lines represented the assumed minimum and maximum nominal limits for crew cabin temperatures (Anderson et al, 2015).

Table 5. PCC measures signifying the similarity in the internal temperatures within the HI-SEAS habitat and the Veggie growth chamber. The higher the percentage, the greater the correlation. Control \#1 data not available as temperature probe hardware for measuring internal temperatures inside growth chamber was received two months into the mission.

Table 6. Correlation between the RH levels in the HISEAS habitat and Veggie growth chamber, based on the PCC values shown below.

\begin{tabular}{ccc}
\hline Trial & PCC & $\boldsymbol{\alpha}$ \\
\hline Test \#1 & $92.5 \%$ & $2.1 \mathrm{E}-12$ \\
\hline Test \#2 & $94.5 \%$ & $4.4 \mathrm{E}-15$ \\
\hline Test \#3 & $93.6 \%$ & $3.1 \mathrm{E}-13$ \\
\hline
\end{tabular}

\begin{tabular}{ccc}
\hline Trial & PCC & $\alpha$ \\
\hline Test \#1 & $52.0 \%$ & $0.5 \%$ \\
\hline Test \#2 & $83.6 \%$ & $2.9 \mathrm{E}-8$ \\
\hline Test \#3 & $72.9 \%$ & $1.3 \mathrm{E}-5$ \\
\hline
\end{tabular}


to the habitat, thus impacting the associated RH level. Average RH ranges for the HI-SEAS habitat and Veggie growth chamber indicate that a nominal, steady-state RH value (40\%) for vehicle atmospheres was achieved based on the average level measured in the habitat $(43.8 \%)$ over the course of the 8-month mission (Anderson et al, 2015).

\section{Carbon Dioxide}

Average $\mathrm{CO}_{2}$ levels, based on five daily measurements, are shown in Fig. 12. These levels were reflective of the gaseous environment within the habitat and assumed to be equivalent to those levels the plants were exposed to inside the growth chamber. Further analysis on the concept of proving positive biological interactions between plants and crew in a deep space mission is recommended.

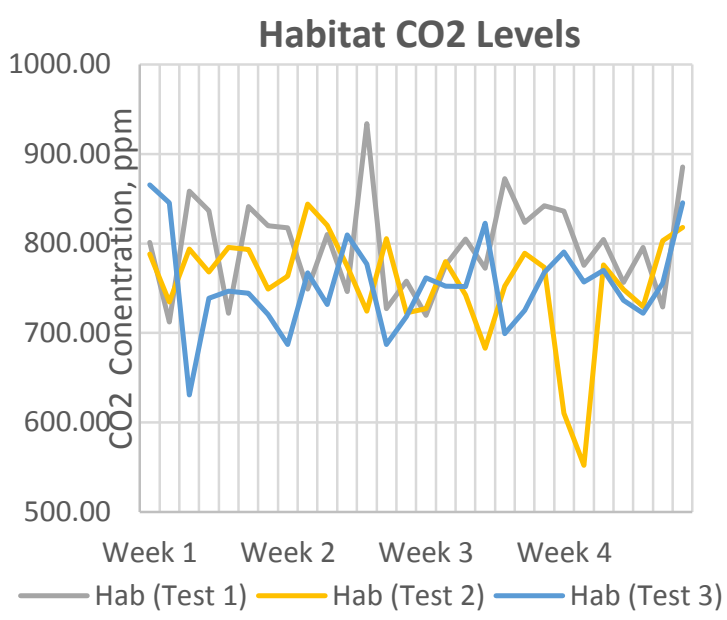

\section{Recommendations}

Figure 12. Carbon dioxide measurements collected in the habitat, assumed to be similar in magnitude to those levels within the Veggie growth chamber.

\section{A. Growth Schedule}

The results from this study produced several parametric values and biological responses. The information gathered can potentially aid in the construction of custom, optimized growth schedules for plants within a microgravity environment. The values listed in Table 7 detailing our lighting schedule provides the opportunity of improvement and refinement, which is ideal when it comes to determining an optimal set of parameters needed for growing plants in an isolated and confined environment over a long period of time.

Table 7. Based on the results and observations collected in the five trails conducted in this study, the PAR levels recommended below are considered "starting points" for the customization of a plant schedule catered to 'Tokyo Bekana' Chinese Cabbage. Results in bold are those tested in this study. It is not, however, the final schedule to be implemented. Further analysis is recommended for confirmation and/or refinement of the limits listed. R:B max limit collected from literature (Massa et al, 2017).

\begin{tabular}{|c|c|c|c|}
\hline \multicolumn{4}{|c|}{ Lighting Schedule for the 28-Day Growout of 'Tokyo Bekana' Chinese Cabbage } \\
\hline Light Combination & $\begin{array}{c}\text { PAR Levels, } \\
\text { pmol*m-2*s-1 }\end{array}$ & $\begin{array}{l}\text { Time, } \\
\text { hours }\end{array}$ & Notes \\
\hline $\mathrm{R}: \mathrm{B}$ & 188.6 $\leq \mathrm{RB} \leq 200$ & $12-14$ & $\begin{array}{l}\text { Time range based on time duration of night cycle (w/ Green } \\
\text { light) }\end{array}$ \\
\hline $\mathrm{R}: \mathrm{B}: \mathrm{G}$ & $\mathbf{1 7 0 . 5} \leq \mathrm{RBG} \leq \mathbf{1 8 8 . 6}$ & $0.5-2$ & $\begin{array}{l}\text { Used for light transition between R:B and G; implemented } \\
\text { daily, twice }\end{array}$ \\
\hline G & $15.83 \leq \mathrm{G} \leq \mathbf{2 2 . 3}$ & $8-10$ & $\begin{array}{l}\text { Low range listed was not tested, only measured in this study; } \\
\text { recommendation based on desire for lessening effects of } \\
\text { green light. More analysis needed to prove this is the case. }\end{array}$ \\
\hline
\end{tabular}

\section{B. Plant-Astronaut Synergy for Long Duration Spaceflight}

The results of this study revealed that certain biological systems, specifically plant growth chambers, may pose several impacts on a space occupied by that of a habitat crew if not planned for or controlled appropriately. These effects, whether those impacting the crew via the plant systems or vice versa, must be accounted for when these inhabitants share both living space and life-supporting consumables. Ideally created in a closed-loop and/or regenerative subsystem within the facility, these mission-critical items need to offer balance both in their consumption and bi-products of use when considering humans and plants "in the loop", together.

Plant systems are emerging as desirable among space travel for manned spaceflight. The crew are the largest consumers of life support commodities, as well as producers of waste products, and plant systems may play a crucial role in regenerating commodities and removing waste products from the spacecraft/habitat's cabin. In addition to 
providing harvests (herbs, fruits, vegetables) for crew consumption, plant systems may serve in the water reclamation process even while providing raw agricultural products. A plant payload taking up residency onboard a spacecraft/habitat can have positive impacts both technically, physically, and psychologically to its crew. Whether they are placed in a common space among astronauts for consumables and wastes control (exercise room, kitchen, crew common area, dining room, etc.), or used in preparation of crew arrival where the plant systems are automated, there are varieties of ways in which plants can serve vital roles in crew daily activities over the course of a long duration, deep space mission.

\section{Design and Planning for Mars}

Over the course of the 8-month mission, many lessons were learned when handing the hardware and collecting data for this study. Martian crews, whether on an orbiting station or in a terrestrial habitat, will need to understand and learn about the role plants will play in their mission. This role, from supplementary food products to simple cabin air replenishment, astronauts must be trained to handle the plants during the maturation, harvesting, and replanting phases as every crew member. Having knowledge in these operations not only benefits the crew in providing fresh herbs and food for the mission but also proven psychological responses for each person. In defining resource prioritization (power, water, living space, etc.), mission planning must define where plants rank far as how much of each must be allocated both in normal conditions and in contingency when any/all requirements are low or unavailable, such as in spacecraft or habitat system anomalies/failures and unanticipated weather events impacting power systems performance.

The use of the Veggie payload provided several additional benefits unanticipated at the start of the mission. Based on the experience gained in using this hardware, as well its daily interaction with the crew during the 8-month Mars analog, several recommendations can be made: full automation, closed-loop, plant health and system status monitoring, multi-purpose. With Veggie and other microgravity plant growth hardware already residing onboard the ISS, success of plants in deep space may find greater success within a habitat on the surface of Mars (Fig. 13).
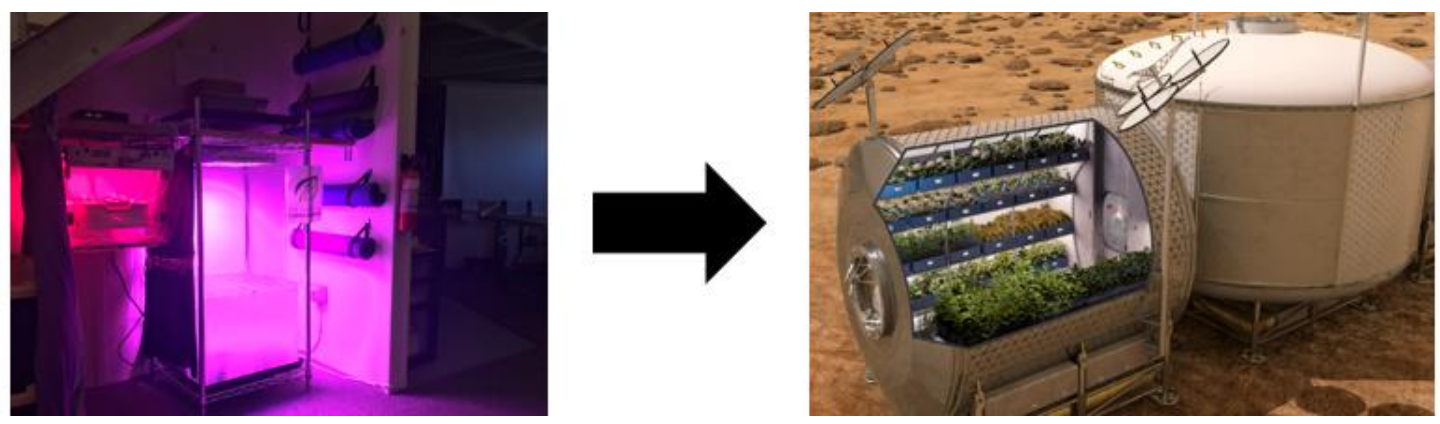

Figure 13. Plants were initially considered to play a "companion role" when designing missions to deep space. Today, plant growth systems are now being considered as serving an "essential part" in missions to cis-lunar space and Mars. Veggie and a plant growth outreach project (left) residing in the HI-SEAS habitat common area (image (right) credit: NASA).

\section{Conclusion}

As missions to deep space continue to evolve and take shape, the payloads required to support human spaceflight in long duration will need to keep pace and meet the primary mission objectives. From space stations to surface habitats, manned BEO missions will require an array of technology to be tested and verified before integration into the mission system architecture, including plant growth hardware. The plant growth systems designed for long duration mission will need to be adaptable to handle definitive sets of growth parameters for supporting various vegetation, all while offering reliability and longevity of the plants and the hardware with minimal crew interaction (outside that of harvesting and replanting). In missions to the Moon and Mars, it has been noted that astronauts tending to microgravity gardens may benefit by having time away from their heavily structured workload by integrating with plants and each other in tending to the plants as a free-time activity (Haeuplik-Meusburger et al, 2012). As stated by cosmonaut Lebedev onboard Salyut-7, "It is amazingly pleasant onboard to look after plants and to observe them. I think that in future long flights there will be a lot of plants. They are simply essential to man in space" (Bluth and Helppie, 1986). 


\section{References}

Garcia, M., "Station Facts and Figures," National Aeronautics and Space Administration [online reference page], URL: https://www.nasa.gov/feature/facts-and-figures [cited March 2017].

Morrow, R.C., Remiker, R.W., Mischnick, M.J., Tuminen, L.K., Lee, M.C., and Crabb, T.M., "A low equivalent system mass plant growth unit for space exploration,” ICES-2005-01-2843, International Conference on Environmental Systems, Kennedy Space Center, FL, 2005.

Massa., G.D., Dufour, N.F., Carver, J.A., Hummerick, M.E., Wheeler, R.M., Morrow, R.C., and Smith, T.M., "VEG-01: VEGGIE Hardware Validation Testing on the International Space Station," Open Agriculture, Vol. 2, pp. 33-41, 2017, pp. 35.

Odeh, R. and Guy, C., "Gardening for therapeutic people-plant interactions during long-duration space missions," Open Agriculture, Vol. 2, pp. 113, 2017, pp. 1.

Richards, J.T., Edney, S., Yorio, N.C., Stutte, G.W., Wheeler, R.M., Goins, G.D., and Cranston, N., "Effects of lighting intensity and supplemental $\mathrm{CO}_{2}$ on yield of potential salad crops for ISS," SAE Tech Paper No. 2004-01-2296, Society of Automotive Engineers, 2004.

Richards, J.T., Edney, S., Yorio, N.C., Stutte, G.W., Wheeler, R.M., Goins, G.D., and Cranston, N., "Effects of lighting intensity and supplemental $\mathrm{CO}_{2}$ on yield of potential salad crops for space exploration," SAE Tech Paper No. 2005-01-2820, Society of Automotive Engineers, 2005.

"Hawai'i Space Exploration and Analog Simulation," HI-SEAS [Home Page], URL: https://hi-seas.org [cited March 2016].

Leon, G.R., Atlis, M.M., and Ones, D.S., "A 1-year, three-couple expedition as a crew analog for a Mars mission," DOI: 10.1177/0013916502034005006, Environment and Behavior, Vol. 34, No. 5, pp. 672-700, 2002, pp. 673.

Wheeler, R.M., "Agriculture for space: People and place paving the way," Open Agriculture, Vol. 2., pp.14-32, 2017, pp.14.

Barta, D.J., Tibbitts, T.W., Bula, R.J., and Morrow, R.C., "Evaluation of light emitting diodes characteristics for a space-based plant irradiation source," Advanced Space Research, Vol. 12, No. 5, pp. 141-149, 1992, pp. 141.

Morrow, R.C., "LED lighting in horticulture," HortScience, Vol. 43(7), pp.1947-1950, 2008, pp.1947.

Massa, G.D., Wheeler, R.M., Morrow, R.C, Levine, H.G., "Growth chambers on the International Space Station for large plants," DOI 10.17660/ActaHortic.2016.1134.29, Acta Horticulturae, Vol. 1134, pp. 215-221, 2016, pp.215.

Anderson, M.S., Ewert, M.K., Keener, J.F., and Wagner. S.A., "Life Support Baselines and Assumptions Document," NASA/TP-2015-218570, Johnson Space Center, Texas, 2015.

Kim, H.K., Goins, G.D., Wheeler, R.M., and Sager, J.C., "Green-Light Supplementation for Enhanced Lettuce Growth under Red and Blue-light emitting Diodes," HortScience, Vol. 39, No.7, pp.1617-1622, 2004, pp.1617.

Folta, K.M. and K.S. Childers, "Light as a growth regulator: Controlling plant biology with narrow bandwidth solid-state lighting systems," HortScience, Vol. 43, pp. 1957-1964, 2008, pp. 1975.

Goins, G.D., Yorio, N.C., Sanwo, M.M., and Brown. C.S., "Seed-to-Seed Growth of Superdwarf Wheat and Arabidopsis Using Red-Light Emitting Diodes (LEDs): A Report on Baseline Tests Conducted for NASA' Proposed Plant Research Unit (PRU)," NASA-TM-11678, 1996.

Heo, J., Lee, C., Chakrabarty, D. and Paek, K.Y., "Growth responses of marigold and saliva bedding plants as affected by monochromic or mixture radiation provided by a Light Emitting Diode (LED)," Plant Growth Regulation, pp. 225-230, 2002, pp. 225.

Folta, K.M. and Maruhnich, S.A., "Green light: a signal to slow down or stop," Journal of Experimental Biology, Vol. 58, No. 12, pp. 3099-3111, 2007, pp. 3105-3106.

Jokhan, M., Shoji, K., Goto, F., Hahida, S., and Yoshihara, T., "Effect of green light wavelength and intensity on

photomorphogenesis and photosynthesis in Lactuca sativa," Elsevier, Central Research Institute of Electric Power Industry, Japan,

pp. 128-133, 2011, pp. 128.

Wang, Y. and Folta., K.M., "Contributions of Green Light to Plant Growth and Development," American Journal of Botany, January 2013 , pp. 70. Zhang, T., Maruhnich, S.A., and Folta. K.M, "Green Light Induces Shade Avoidance Symptoms," Plant Physiology, Vol. 157, pp. 1528-1536, 2011, pp. 1529.

Steinberg, S.L., Ming, D.W., and Henninger, D., "Plant Production Systems for Microgravity: Critical Issues in Water, Air, and Solute Transport Through Unsaturated Porous Media,"NASA/TM-2002-210774, 2002.

Massa. G.D., Dufour, N.F., and Smith, T.M., "Veggie Hardware Validation Test Preliminary Results and Lessons Learned," Kennedy Space Center, Florida, 2014, pp.1.

Tsao, D. and Okos, M., "Physiological Response of Plants Grown on Porous Ceramic Tubes," NASA/CR-97-206741, Purdue University: Agricultural and Biological Engineering Department, pp.10, 1997.

Savage, W., "The Coupling of Solution Chemistry to Plant Nutrient Demand In An On-Demand Nutrient Delivery System,” Doc, ID 19980218874, San Jose State University, California, 1998, pp.3.

Massa, G., Newsham, G., Hummerick, M.E., Caro, J.L., Stutte, G.W., Morrow, R.C., and Wheeler, R.W., "Preliminary Species and Media Selection for the Veggie Space Hardware," Gravitational and Space Research, Vol. 1, No.1, pp. 96-106, October 2013, pp. 101-102, 104.

Massa, G., Hummerick, M., Spencer, L., and Smith, T., "Veggies ISS Validation Test Results and Produce Consumption," KSC-E-DAA-TN27798, Kennedy Space Center, FL, 2015, pp.2.

Massa, G.D., Wheeler, R.M., Stutte, G.M, Richards J.T., Spencer, L.E., Hummerick, M.E., Douglas, G.L, and Sirmons, T., "Selection of Leafy Green Vegetable Varieties for a Pick-and-Eat Diet Supplement on ISS," $45^{\text {th }}$ International Conference on Environmental Systems, ICES-2015-252, Kennedy Space Center, FL, 2015, pp.3.

Massa, G.D, Newsham, G., Hummerick, M.E., Morrow, R.C., and Wheeler, R.M., "Plant Pillow Preparation for the Veggie Plant Growth System on the International Space Station,” KSC-E-DAA-TN30342, Kennedy Space Center, FL, 2016, pp.1-5.

"Hawaii County Water Use and Development Plan Update," County of Hawaii Department of Water Supply [online public document, URL: http://www.hawaiicounty.gov/water-supply/ [cited April 2017].

Haeuplik-Meusburger, S., Patterson, C., Schubert, D., and Zabel, P., "The Road Less Traveled: Greenhouses and their Humanizing Synergies,"

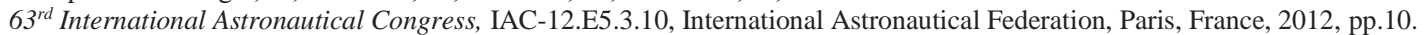

Bluth, B.J. and Helppie M., "Soviet Space Stations as Analogs," 2 nd ed., NASA-CR-180920, NASA Headquarters, Washington, D.C., 1986, pp. 43. 